\title{
Effect of temperature in electrical magnitudes of LED and HPS luminaires
}

\author{
Carolina Brusil \\ Escuela Politécnica Nacional, \\ Department of Electric and Electronic, Electrical Engineering \\ Av. Ladrón de Guevara, Quito, Ecuador \\ mayte.brusil@epn.edu.ec
}

\section{Francisco Espín}

Instituto de Investigación Geológico y Energético Av. de la República E7-263 y Diego de Almagro, Quito, Ecuador francisco.espin@geoenergía.gob.ec

\section{Carlos Velásquez}

Instituto de Investigación Geológico y Energético Av. de la República E7-263 y Diego de Almagro, Quito, Ecuador carlos.velasquez@geoenergía.gob.ec

Dept. of Applied Mathematics, University of Alicante, Apdo. 99, 03080, Alicante, Spain cavf1@alu.ua.es

\begin{abstract}
Temperature effects on luminaires is usually referred to light output, that is luminaire efficiency. However, the effect on electrical magnitudes as power, current and third current harmonic is not widely studied. One major technology, Light-emittingdiode (LED) is fast replacing the other types of lighting all over the world, this opens the interrogate of how is temperature affecting LED luminaires development and how different is this effect compared to other technologies. This paper analyses these effects on LED luminaires of different wattage and one high pressure SODIUM luminaire. Luminaires were measure in two different environments, the first stage with a constant temperature-controlled system $\left( \pm 1^{\circ} \mathrm{C}\right)$ and the second one without a temperature-controlled system. The tests were performed on three samples of LED luminaires with different power ratings and one sample of SODIUM luminaire. It was found that the third current harmonic is directly related to temperature while power and current are inversely related.
\end{abstract}

Keywords: LED, SODIUM, temperature dependency, current, $3^{\text {rd }}$ current harmonic, measurement

\section{INTRODUCTION}

Light-emitting-diode (LED) lighting is a growing technology that is being installed across the world, replacing some conventional technologies as high intensity discharge (HID) and compact fluorescent lamps (CFLs) [1]. While CFLs are used in domestic application, the High-pressure sodium (HPS, SODIUM) lamps are particularly suited to outdoor lighting and use on streets and highways.

LED lighting is a viable solution for many applications due to high energy efficiency and long life [2]. Its applications vary from industrial and commercial lighting to outdoor and public illumination, but while its diverse applications and strengths increase every day there is a significant disadvantage that must be taken into account, decreased performance with increased temperature [3].
LED luminaires operate at relatively high electrical input power, which requires good thermal management [4]. This may mean higher maintenance costs for LED technology; however, this technology is not the only one who seems affected by temperature. Discharge lamps are generally sensitive to outside temperature [5] and according to their constructive characteristics they will be more or less affected.

LEDs also require a constant current source from a low-DC voltage source obtained from the AC mains [6]. LED driver is the one who converts the input $A C$ voltage of the utility grid into low DC voltage which is compatible with the LED and regulates the flow of DC current through the LED to control the extent of illumination [7].

Junction temperature, which refers to the temperature of active region in LEDs, is an important parameter. It in- 
fluences the performances of LEDs, such as efficiency, output power, reliability, peak wavelength shift, and spectral width [8]. Increase in LED die junction temperature, due to power dissipation or changes in ambient temperature, significantly impacts its light output as well as peak wavelength. Therefore, thermal effects on LED behavior must be considered and LED junction temperature must be maintained below the maximum specified limit [9].

Performance characteristics of LED light sources are specified for a rated current and for a specific LED die junction temperature (ex. $T_{j}=85^{\circ} \mathrm{C}$ ). Since most LEDs operate at environment temperatures above or less to $25^{\circ} \mathrm{C}$, reference values and the light output should be based on the anticipated operating temperatures [10].

Higher ambient temperature leads to higher junction temperatures [11]. The ambient temperature and the drive current both affect the junction temperature of LED [12]. Higher LED die junction temperatures, resulting from increased power dissipation or changes in ambient temperature, can have a significant effect on light output [10].

As indicated in [12], as junction temperature increases LED's current decreases, which in turn cause decrease in light output.

The effect of temperature and current on luminous efficiency of high-power LED is analyzed in [13]. Their measurements were done with a high precision constant current, and a voltage DC stabilizer supplied the power of LED. The current-voltage characteristics were obtained with the analyzer and the luminous efficiency values at the temperature from $20^{\circ} \mathrm{C}$ to $80^{\circ} \mathrm{C}$ and the current from $10 \mathrm{~mA}$ to $350 \mathrm{~mA}$ was measured with the analyzer as well. When the drive current is $10 \mathrm{~mA}$; the efficiency at $80^{\circ} \mathrm{C}$ is $12.5 \%$ lower than the efficiency at $20^{\circ} \mathrm{C}$. When the drive current is $305 \mathrm{~mA}$, the efficiency at $80{ }^{\circ} \mathrm{C}$ is just $6 \%$ lower than of $20^{\circ} \mathrm{C}$, concluding that the changing rate of efficiency with temperature becomes less when the drive current is larger.

Another interesting aspect is generation of higher harmonics by luminaires; especially LED luminaires in which LED driver is the one who controls the current injected into the LED, the total harmonic distortion in input current (THDI) [9] and the power factor (PF).

Highly distorted current has been a concern with other technologies as CFL lamps and a large number of studies were conducted over the past decade [1]. One of them [14], analyses the harmonic impacts from compact fluorescent lights on distribution systems, concluding that high penetration levels of CFLs with high distortion, electronic ballasts can result in unacceptable voltage distortion levels on distribution systems. Similarly, LED lighting is creating significantly distorted current, different LED lamps types with different power levels will have different THDI [8].

Permissible limits for harmonic current emissions in lighting equipment are specified in IEC 61000-3-2 [15]. LED sources fall in the class $C$ category of equipment with input power less than $25 \mathrm{~W}$, and LED luminaires falls in the category of class $C$ of equipment with input power greater than $25 \mathrm{~W}$. According to the input power the limits are less or more restrictive. For luminaires (> $25 \mathrm{~W}$ ) limits are clearly specified and highly restrictive.

Many studies have shown a bad quality of LED drivers included in such lamps. These drivers cause noise and can lead to bad quality electrical energy. The paper [16] studied electrical parameters for wirelessly controlled color and dynamic white LED lamps of the Hue type which emit optical radiation in three different colors: Green, red and blue, or three CCT values. Measurements of the total harmonic distortion THD and power factor PF coefficients were performed for different RMS values of feeding voltage. It was showed that the level of distortions increases with the decrease in the RMS voltage. The THD values of the supplying current strongly depend on the color of the emitted light and feeding voltage. The highest THD value was obtained for neutral white light and is 59\%, while the lowest THD value was obtained for warm white light and is equal to $46 \%$.[16]

Another study [17] has shown that a switched power supply incorporated in the LED lamps and used to control the light diodes cause very strong distortions of the current signal and hence generates higher harmonics of the current. This study found that when the lighting system operates solely with one type of light source, the harmonic distortion of current remains constant irrespective of the change of power (pieces) of the light fixtures. Completely different characteristics of the total harmonic distortion of current intensity THDi in the function of the active power of load were obtained when LED light sources manufactured by various companies operated at the same time.[17]

Similarly, study [18] analyzes the impact of load resistance (or LED module load) on THD for two types of LED lamp power supply. THD coefficient values were determined for several different values of LED module load. It was proved that the power supply of one type of lamp generates smaller distortions, and THD does not exceed $26 \%$ when it is loaded with an LED module. The second lamp power supply type is characterized by the THD coefficient which is three times higher.

Reference [19] shows the analysis of low-wattage LED bulbs $4 \mathrm{~W}$ and $7 \mathrm{~W}$ in cool white and warm white with and without harmonic filters in their drivers. This paper evaluates the harmonic parameters of low wattage warm white and cool white LED lamps of different ratings manufactured by the same brand. This study presented the experimental results on harmonic generation from both warm and cool white LED bulbs that are currently used in residential, commercial, and industrial lighting. The tested lamps THDi values range from $9.5 \%$ to $127.5 \%$. The $4 \mathrm{~W}$ warm white LED has a $127.5 \%$ harmonic distortion level and 7W cool white LED which has $119.7 \%$ harmonic distortion. The warm white LED bulbs shown a higher contribution towards harmonic emission compared to cool white LED bulbs. 
The present work detailed evaluation of current, and power behavior of 3 LED luminaires LEDEX (150 W, 180 $\mathrm{W}$ and $240 \mathrm{~W}$ ) [20] and 1 sodium luminaire Schreder Ambar 3 (400 W) [21] during temperature changes, see Fig. 1. Additionally, the behavior of the third current harmonic is presented in each of the tests performed.

This type of luminaire is of special interest. The sodium is still used to illuminate certain roads and the replacement by LED luminaires is typically using luminaires with powers similar to those studied in this work. The behavior of the electrical parameters is analyzed that could influence electrical network power quality.

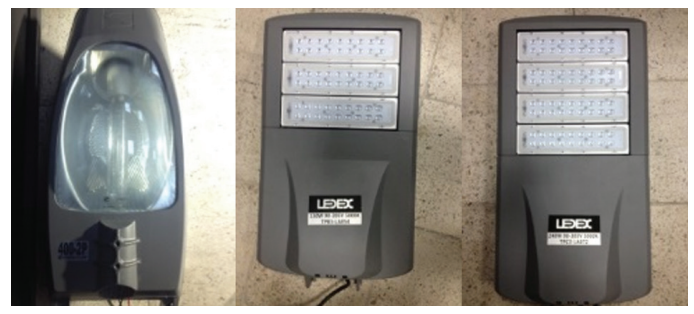

Fig. 1. Experimental luminaires pictures

Primary purpose is to compare the electrical behavior of both technologies and secondary is to analyze the influence of temperature on luminaire performance.

\section{METHODOLOGY}

The authors measured four luminaires (1 SODIUM, 3 LEDs) for public lighting in the experiment. The experiment consisted of 2 stages. First, the experiment was realized in a room without temperature control. Second, they were subjected to measurements (according to Fig. 2) in a room with a constant temperaturecontrolled system $\left( \pm 1{ }^{\circ} \mathrm{C}\right.$, measurements in under air conditioning conditions).

Table 1 shows the characteristics of each measured luminaire.

Table 1. Technical characteristics for tested luminaires

\begin{tabular}{|cccc|}
\hline Name & $\begin{array}{c}\text { Nominal } \\
\text { Power [W] }\end{array}$ & $\begin{array}{c}\text { Luminous } \\
\text { Flux [lm] }\end{array}$ & Technology \\
\hline LED $15000 \mathrm{~K}$ & 150 & 19500 & LED \\
\hline LED 2 $5000 \mathrm{~K}$ & 180 & 23400 & LED \\
\hline LED 3 $5000 \mathrm{~K}$ & 240 & 31200 & LED \\
\hline SODIUM 2300 K & 400 & 46069 & HPS
\end{tabular}

Each luminaire is tested individually and connected to a single-phase voltage of $240 \mathrm{~V}$ using an AC controlled voltage source ( $\pm 2 \%)$.

The observation period is bigger than one day. This is necessary to observe changes in electrical magnitudes with the influence of temperature variations during a day. The measurement aggregation time interval is 10 minutes for parameter magnitudes: power, current, harmonic distortion and LED driver temperature, and 1 minute for environment temperature.

Electrical measurements are made with two electrical power quality analyzers (METREL MI 2892, SONEL PQM711). Temperature measurements are made with METREL temperature probe and Testo $174 \mathrm{H}$ Mini temperature and humidity datalogger, all calibrated in Laboratory that has ISO/IEC 17025 certificate. The METREL temperature probe measures the driver temperature inside the luminaire. Testo data logger measures the environmental temperature. Figure 2 shows the measurement scheme.

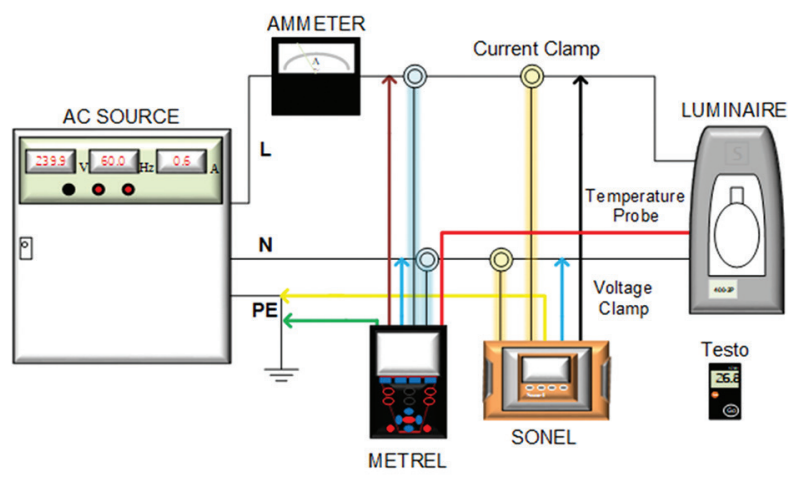

Fig. 2. Schematic diagram of experimental setup

Measurements are carried out in two scenarios, the first without air conditioning and the second in an airconditioned room at controlled temperature of $25{ }^{\circ} \mathrm{C}$ $\pm 1^{\circ} \mathrm{C}$. So, each luminaire is tested two times for more than one day.

During the measurements, there were no other influences on the temperature variations. The test room is an dark room, that is, there are no windows that allow external light to enter. Additionally, during the period in which the luminaires were measured, the door was kept closed.

The measurement curve results are smoothen and normalized using a computer program. The curves were compared with the Pearson correlation coefficient between each electrical parameter and temperature.

$$
r=\frac{\sum_{i=1}^{n}\left(T_{i}-\bar{T}\right)\left(x_{i}-\bar{x}\right)}{\sqrt{\sum_{i=1}^{n}\left(T_{i}-\bar{T}\right)^{2}} \sqrt{\sum_{i=1}^{n}\left(x_{i}-\bar{x}\right)^{2}}}
$$

Where, $T$ is temperature and $\mathrm{x}$ represents current, power and thirth harmonic in each calculation. The values were found in Origin 9.1 software.

It is interesting to observe the reaction of the electrical parameters such as power, the third harmonic and current as a function of the temperature variation at a constant voltage since they influence the power quality of the electrical network.

It is expected to find relationships between electrical parameters and temperature variations at a constant power supply in a thermally controlled environment as well as in uncontrolled environment. 


\section{RESULTS AND DISCUSSION}

In this section, the measurements results are summarized in graphs. Measurements made under constant temperature conditions represent Scenario 2 and measurements without air conditioning represent Scenario 1.

\subsection{ELECTRICAL POWER AND TEMPERATURE}

The next figures show the results of power and temperature in each luminaire.

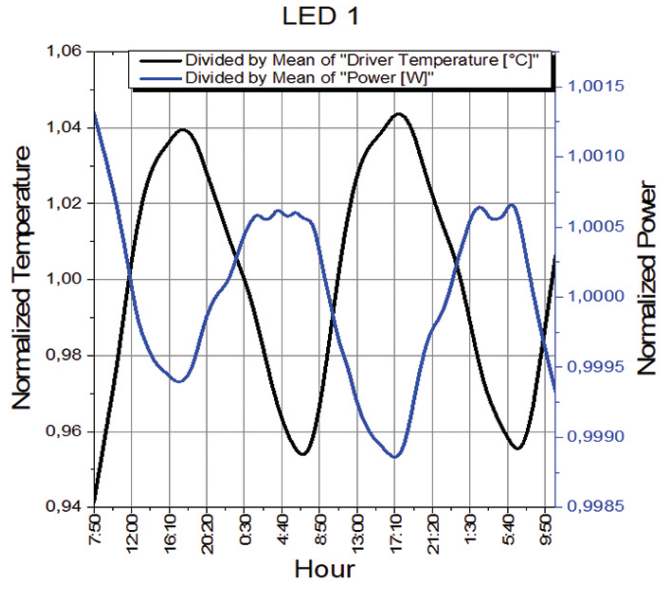

LED 2

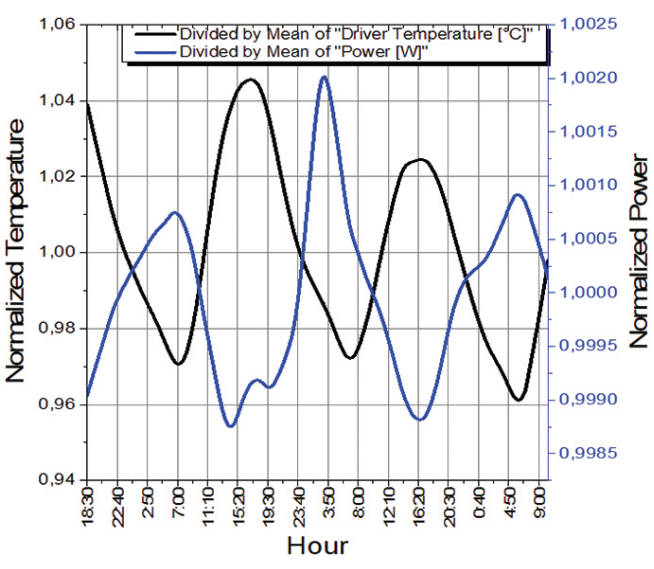

LED 3

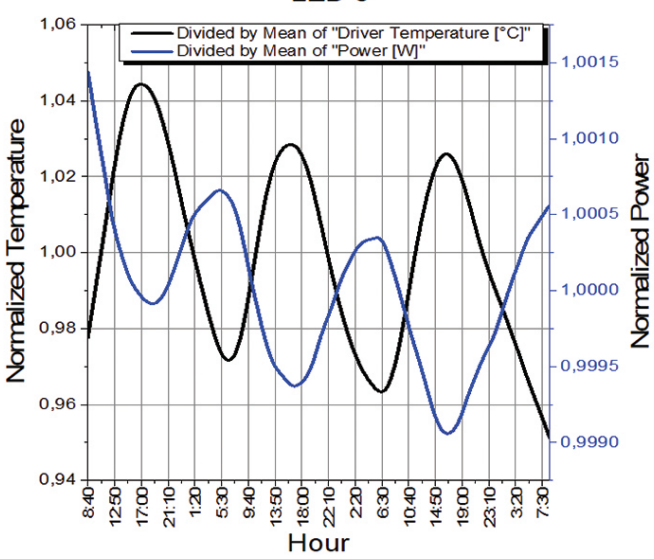

Fig. 3. Luminaire's driver temperature divided by mean (LED 1: $48.1^{\circ} \mathrm{C}$; LED 2: $47.3^{\circ} \mathrm{C}$; LED 3: $60.9^{\circ} \mathrm{C}$ ) and power divided by mean (LED 1: $157.9 \mathrm{~W}$; LED 2: 169.9 W; LED 3: 236.4 W)
Figure 3 represents LED driver temperature and power results at test conditions of Scenario 1. It shows that LED driver temperature behaves in the same way as environmental temperature. The behavior of current and power is identical, since the supply voltage is constant (Figure 4). The correlation between temperature and power at Scenario 1 of all tested luminaires are presented in Table 2.

Figure 4 shows the results of room temperature and current at Scenario 1, in that condition the next results are observed:

- For SODIUM luminaire, temperature variations over the course of a day in the room without air conditioning are around $4.7^{\circ} \mathrm{C}$, with this temperature variation electrical power change $2 \mathrm{~W}$. The correlation coefficient $r$ is $(94 \pm 1) \%$ and there is a strong and direct correlation between power and temperature in sodium luminaire.

- For LED 1 luminaire, a temperature variation of 5.6 ${ }^{\circ} \mathrm{C}$ changes electrical power around $0.5 \mathrm{~W}$. There is a strong correlation between temperature and power ( $r=94 \pm 1 \%)$, but in this case, there is an inverse correlation.

- For LED 2 luminaire, a temperature variation of 4.9 ${ }^{\circ} \mathrm{C}$ changes electrical power around $0.8 \mathrm{~W}$, again, there is an inverse correlation between temperature and power.

- For LED 3 luminaire, a temperature variation of 5.7 ${ }^{\circ} \mathrm{C}$ changes electrical power around $0.8 \mathrm{~W}$, there is an inverse correlation between temperature and power.

Table 2. Correlation coefficients between temperature and power, Scenario 1

\begin{tabular}{|c|c|c|}
\hline & \multicolumn{2}{|c|}{ Correlation Coefficient r (\%) } \\
\hline & $\begin{array}{l}\text { Power vs. room } \\
\text { Temperature }\end{array}$ & $\begin{array}{c}\text { Power vs. Driver } \\
\text { Temperature }\end{array}$ \\
\hline LED 1 & $(94 \pm 1) \%$ & $(88 \pm 3) \%$ \\
\hline LED 2 & $(86 \pm 1) \%$ & $(85 \pm 3) \%$ \\
\hline LED 3 & $(54 \pm 2) \%$ & $(55 \pm 7) \%$ \\
\hline SODIUM & $(94 \pm 1) \%$ & - \\
\hline
\end{tabular}

Figure 5 represents the results of temperature and current at Scenario 2. Under controlled temperature test conditions, there is not significant correlation between room temperature and power, the correlation coefficient for SODIUM luminaire is $(50 \pm 3) \%$, LED luminaires also have lower correlation coefficients. The correlation coefficients for LED 1, LED 2 and LED 3 reduce to $75 \%, 16 \%$ and $18 \%$ respectively.

In Scenario 2 test conditions LED luminaires have greater electrical current than Scenario 1. 

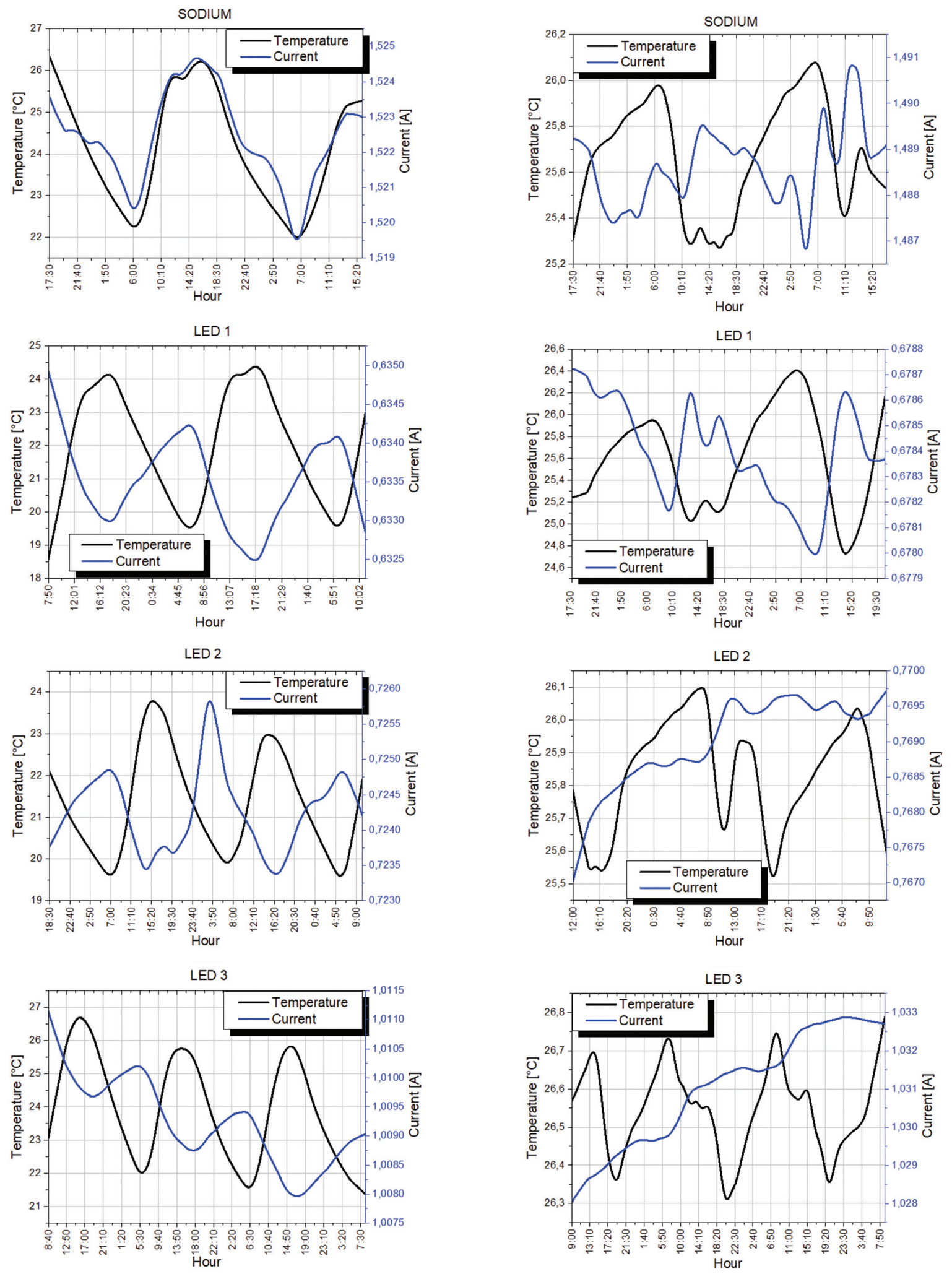

Fig. 4. Luminaires current and room temperature, Scenario 1

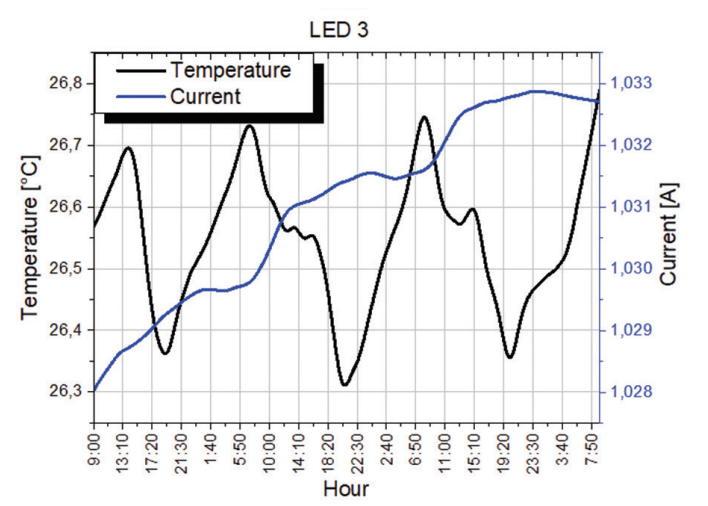

Fig. 5. Luminaires current and room temperature, Scenario 2

\subsection{CURRENT AND TEMPERATURE}

The current is directly related to power. The Figure 4 and Figure 5 show the results of room temperature and current at Scenario 1 and Scenario 2, respectively. Driver temperature behaves in the same way of room temperature. Their results of correlation coefficient are shown Table 3.

Figure 4 shows the results for current and temperature of luminaires at test conditions of Scenario 1, for SODIUM luminaire the behavior of current is the same as power and both correlation factors are similar (Table 2 and 3 ).

However, with a temperature variation of $4.7^{\circ} \mathrm{C}$ current changes are not significant. 
For LED luminaires correlation between current and temperature is inversely as for power, and there is strong correlation for LED luminaries of $150 \mathrm{~W}$ and 180 W. Despite the high correlation between temperature and current the changes in this last are not significant.

Table 3. Correlation coefficient between temperature and current of luminaires, Scenario 1

For LED 3 there is poor correlation due to a continuous current decrease on the luminaire, however peaks and valleys of temperature are reflected in current.

Figure 5 shows the results with air conditioning of room temperature and current. At controlled temperature test conditions, correlation coefficients between temperature and current are similar to correlation coefficients between temperature and power.

Table 3. Correlation coefficient between temperature and current of luminaires, Scenario 1

\begin{tabular}{|c|c|c|}
\hline & \multicolumn{2}{|c|}{ Correlation Coefficient r (\%) } \\
\hline & $\begin{array}{c}\text { Current vs. Environment } \\
\text { Temperature }\end{array}$ & $\begin{array}{l}\text { Current vs. Driver } \\
\text { Temperature }\end{array}$ \\
\hline LED 1 & $(93 \pm 1) \%$ & $(91 \pm 3) \%$ \\
\hline LED 2 & $(84 \pm 1) \%$ & $(80 \pm 4) \%$ \\
\hline LED 3 & $(8 \pm 19) \%$ & $(9 \pm 56) \%$ \\
\hline SODIUM & $(95 \pm 1) \%$ & - \\
\hline
\end{tabular}

\subsection{THIRD CURRENT HARMONIC AND TEMPERATURE}

Figure 6 shows that $3^{\text {rd }}$ harmonic is the most significant in HPS luminaire and LED luminaires. LED luminaires, unlike HPS luminaire, present high order harmonics. For HPS luminaire, high order harmonics reach zero.

Considering that $3^{\text {rd }}$ harmonic is the most significant, only $3^{\text {rd }}$ harmonic is analyzed in section 3.4 .

Third current harmonic and temperature results show that LED luminaires have a strong and direct correlation between third current harmonic and temperature.

Table 4. Correlation coefficient between temperature and $3^{\text {rd }}$ current harmonic, Scenario 1

\begin{tabular}{|c|c|c|}
\hline & \multicolumn{2}{|c|}{ Correlation Coefficient r (\%) } \\
\hline & $\begin{array}{l}\text { Third harmonic vs. } \\
\text { Environment Temperature }\end{array}$ & $\begin{array}{l}\text { Third harmonic vs. } \\
\text { Driver Temperature }\end{array}$ \\
\hline LED 1 & $(95 \pm 1) \%$ & $(96 \pm 2) \%$ \\
\hline LED 2 & $(93 \pm 1) \%$ & $(83 \pm 3) \%$ \\
\hline LED 3 & $(93 \pm 1) \%$ & $(97 \pm 1) \%$ \\
\hline SODIUM & $(34 \pm 5) \%$ & - \\
\hline
\end{tabular}

In table 4, all LED luminaires have strong and direct correlation between temperature and third current harmonic, compared with previous results, third current harmonic is the most related to temperature.
The mean results of third current harmonic expressed as percentage of the fundamental current and their changes due to temperature are $16.2 \%$ for SODIUM, $4.3 \%$ for LED 1, $5.4 \%$ for LED 2 and $6.2 \%$ for LED 3.

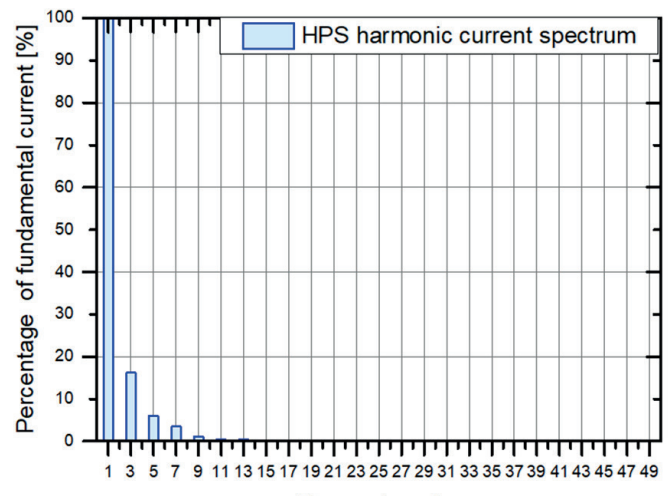

Harmonic order
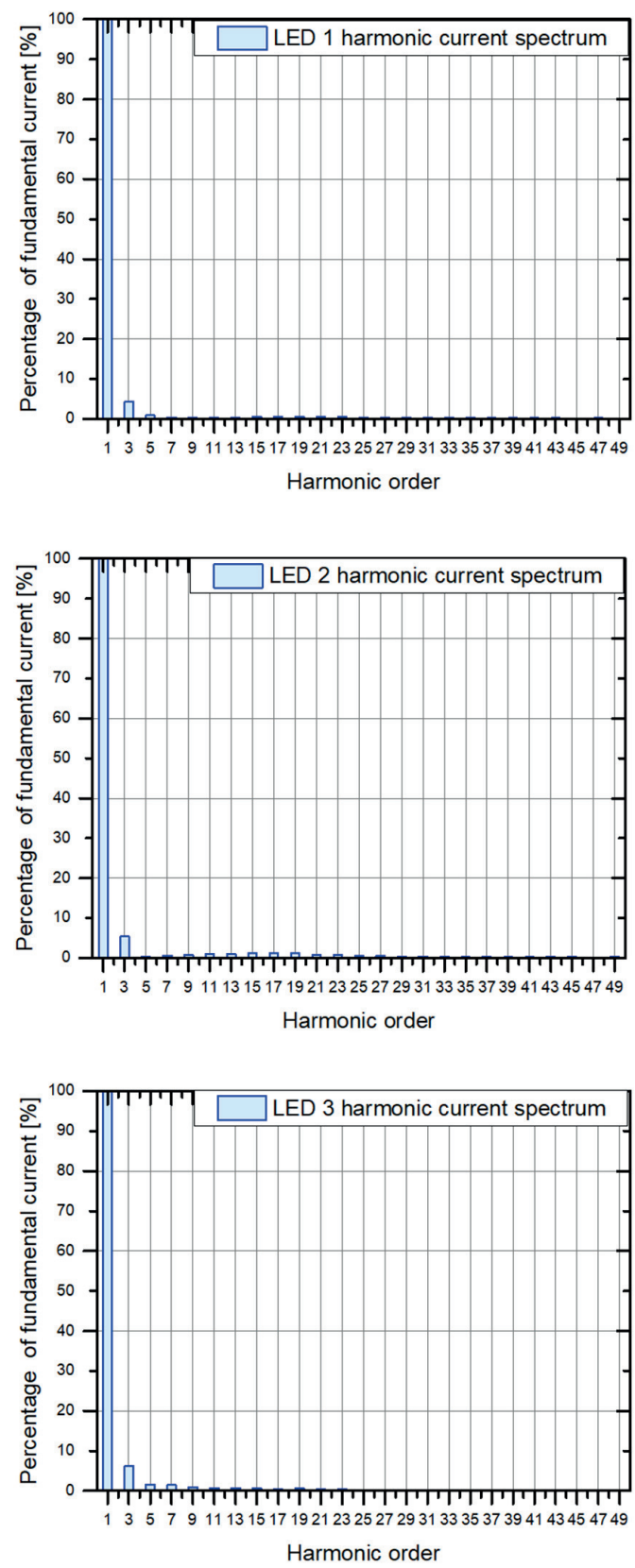

Fig. 6. Luminaires harmonic current spectrum 

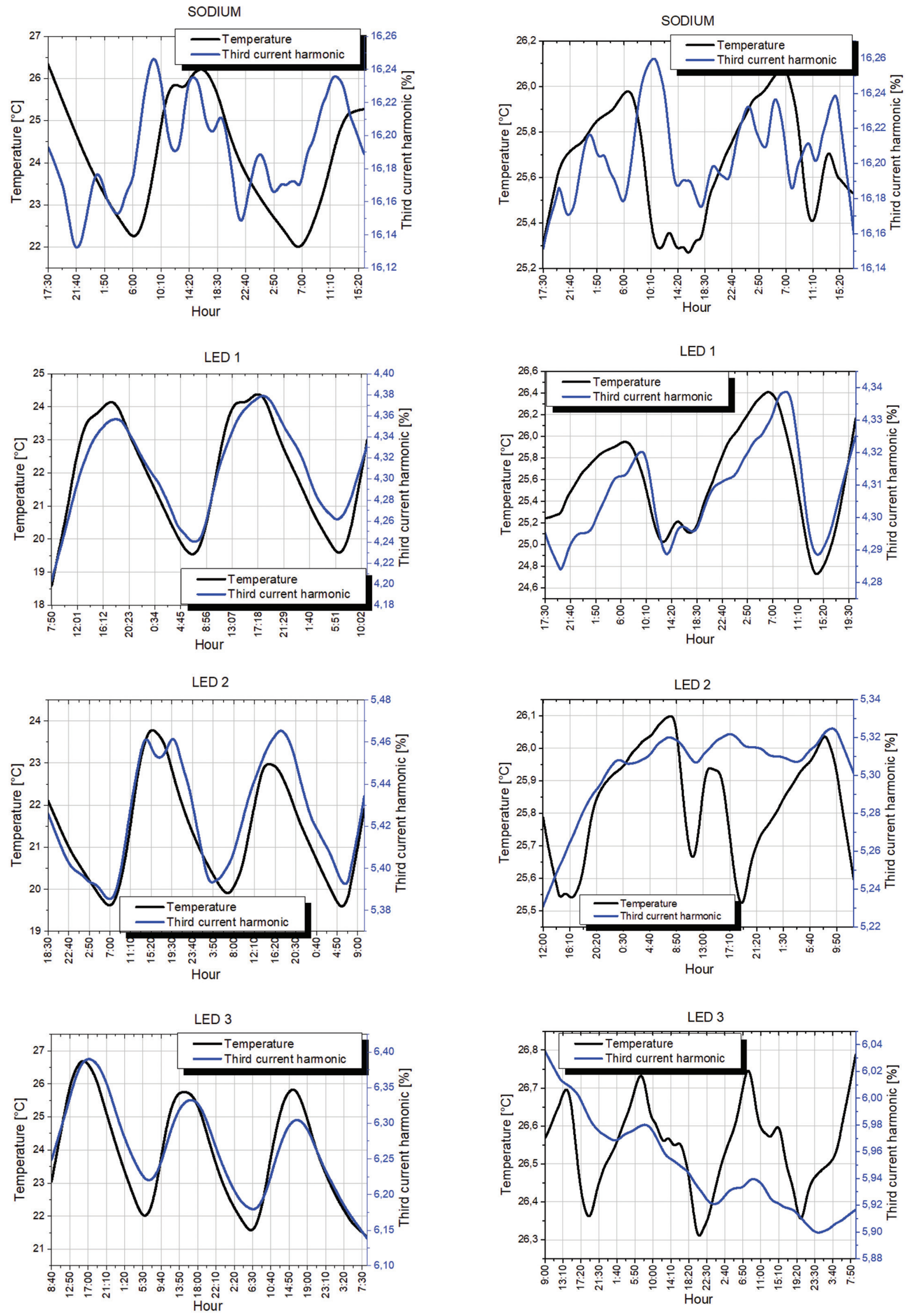

Fig. 7. Luminaires 3rd current harmonic and temperature, Scenario 1

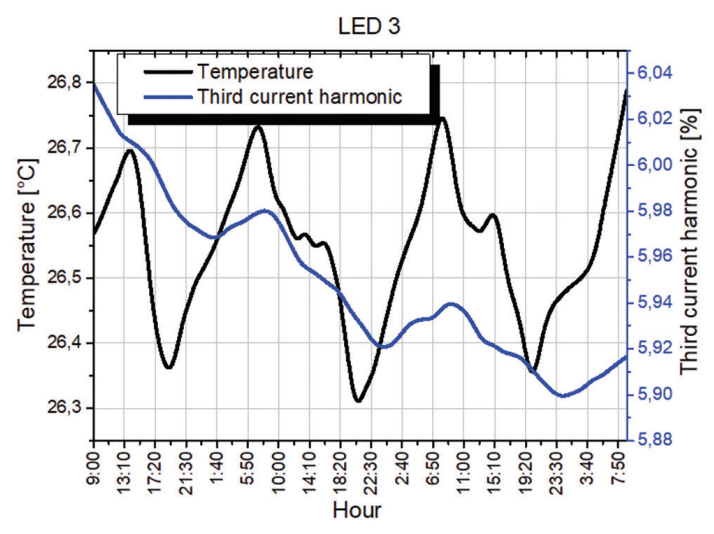

Fig. 8. Luminaires 3rd current harmonic and temperature, Scenario 2

SODIUM luminaire generates higher current harmonic distortion than LED luminaires, however all luminaires meet the limits of the standard IEC 61000-3-2. These average results do not change significantly at Scenario 2. 
In Figure 7, LED 1, LED 2 and LED 3 third current harmonic expressed as percentage changes $0.1 \%, 0.11 \%$ and $0.2 \%$, with a temperature variation of $5.6^{\circ} \mathrm{C}, 4.9^{\circ} \mathrm{C}$ and $5.7^{\circ} \mathrm{C}$ respectively, for SODIUM luminaire there is not strong correlation between third current harmonic and temperature, however a temperature variation of $4.7^{\circ} \mathrm{C}$ changes $0.31 \%$ of third current harmonic.

Figure 8 represents room temperature and third harmonic results of luminaires at test conditions of Scenario 2. At controlled temperature test conditions the correlation factor is reduced. LED 1 correlation coefficient reduces to $(79 \pm 1) \%$ and third current harmonic changes are also less $(<0.1 \%)$, correlation coefficients of the other luminaires are similar to correlation coefficients between temperature and power.

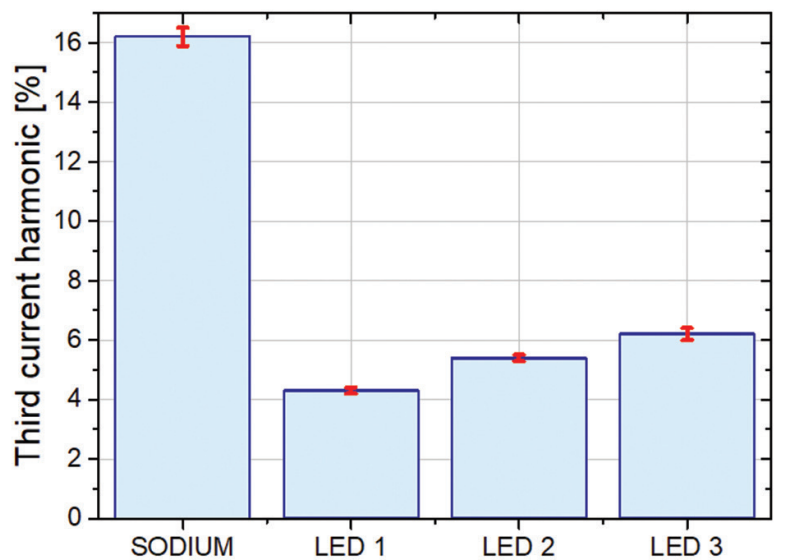

Fig. 9. Luminaires third current harmonic expressed as percentage of the fundamental current

Total results at Scenario 1 are summarized in the next figures and show:

- The dependence of current and power variations, which are always on the same direction.

- SODIUM luminaire power, current and third current harmonic measurements are directly related to temperature. High temperatures facilitated electrical discharge inside SODIUM lamps, but thanks to the ballast current flow remains almost constant (Figure 10).

- LED luminaires power and current are inversely related to temperature (Figure 11, 12, 13), an increasing temperature decrease luminaire's current. As indicated in [9], higher LED die junction temperatures, resulting from changes in ambient temperature reduces the current flow, however LED's drivers maintain current and power almost constant, LED's drivers are also responsible of the low third current harmonic on LED luminaires.

- Although the percentage of current harmonics increases as LED luminaire power increases, this is still much lower than the obtained for SODIUM luminaire.

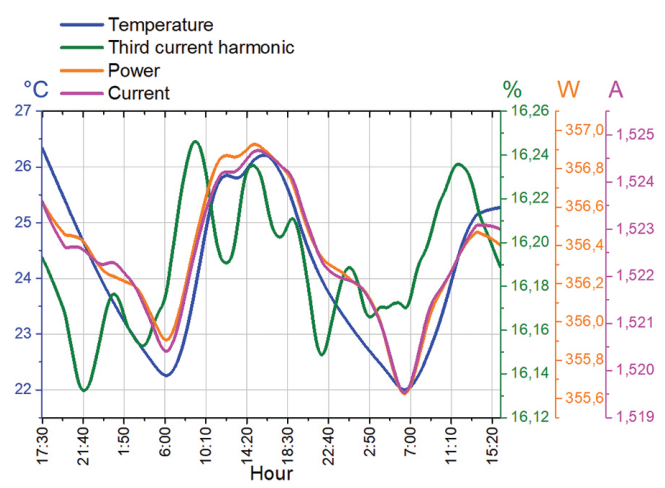

Fig. 10. SODIUM luminaire current, power, third current harmonic and temperature

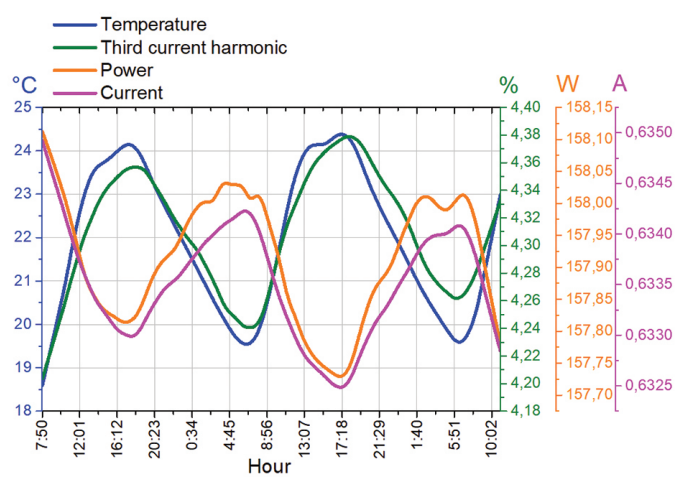

Fig. 11. LED 1 luminaire current, power, third current harmonic and temperature

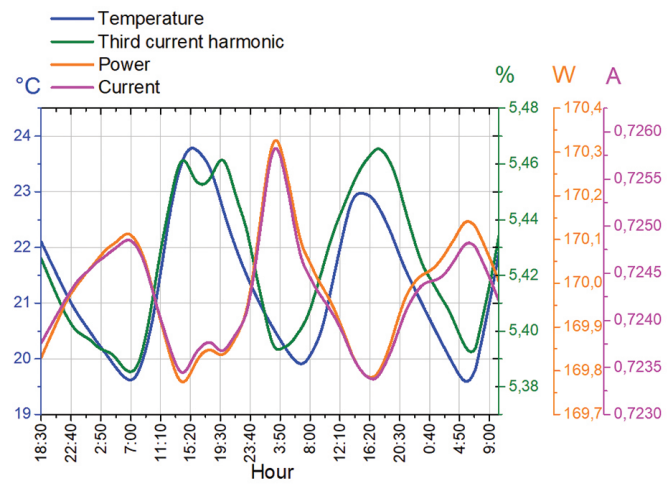

Fig. 12. LED 2 luminaire current, power, third current harmonic and temperature

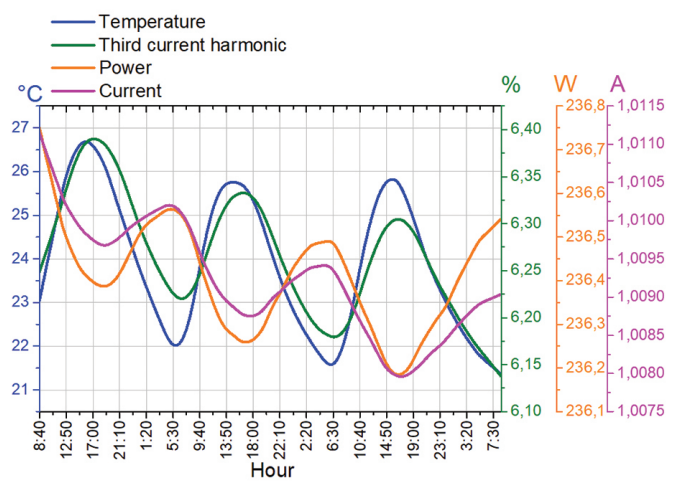

Fig. 13. LED 3 luminaire current, power, third current harmonic and temperature 


\section{CONCLUSION}

LED luminaires are sensitive to temperature in both Scenarios. Third current harmonic is directly related to temperature while power and current are inversely related. Power of LED luminaires changes around 0.1 $\mathrm{W} /{ }^{\circ} \mathrm{C}$, however, the changes in current magnitudes are not significant, this shows the good performance of LED drivers.

LED 3 correlation coefficients are lower compared with correlation coefficients of LED 1 and LED 2 luminaires due to a continuous current decrease which affects the calculation of correlation coefficients, however the results obtained for third current harmonic agrees with the results of the other LED luminaires.

SODIUM luminaire is sensitive to significant temperature changes. Current, power and third current harmonic are directly related to temperature, current and power have strong correlation coefficients with temperature, however, third current harmonic has a poor one. Power of SODIUM luminaire changes around 0.4 $\mathrm{W} /{ }^{\circ} \mathrm{C}$. At controlled temperature test conditions coefficients between temperature and electrical magnitudes are not significant for SODIUM luminaire.

LED luminaires generate lower current distortion than SODIUM luminaire. LED's drivers of the luminaires tested generate fairly low harmonic distortion values and high-power factor.

\section{REFERENCES}

[1] P. Verma, N. Patel, N.-K. C. Nair, "Power quality impacts during CFL to LED transition", Proceedings of the Australasian Universities Power Engineering Conference, Brisbane, QLD, Australia, 25-28 September 2016, pp. 1-6.

[2] S. Uddin, H. Shareef, A. Mohamed, M. A. Hannan, "An analysis of harmonics from LED lamps", Proceedings of the Asia-Pacific Symposium on Electromagnetic Compatibility, Singapore, 21-24 May 2012, pp. 837-840.

[3] A. Aranda, I. Zabalza, S. Díaz, E. LLera, "Energy efficiency in building facilities and equipment", $1^{\text {st }}$ Edition, Zaragosa: University Presses, 2010.

[4] G.-H. Ryu, H.-Y. Ryu, "Analysis of the Temperature Dependence of Phosphor Conversion Efficiency in White Light-Emitting Diodes", Journal of the Optical Society of Korea, Vol. 19, No. 3, 2015, pp. 311-316.

[5] Stouchlighting, "Lighting Comparison: LED versus HID Lights", https://www.stouchlighting.com/ blog/lighting-comparison-led-versus-hid

(Accessed: 2021).

[6] S. Uddin, H. Shareef, A. Mohamed, "Power quality performance of energy-efficient low-wattage LED lamps", Measurement, Vol. 46, No. 10, 2013, pp. 3783-3795.

[7] H. Swami, A. K. Jain, I. H. Azad, N. Meena, “Evaluation of input harmonic characteristics of LED lamps connected to utility grid", Proceedings of the IEEMA Engineer Infinite Conference, New Delhi, India, 13-14 March 2018, pp. 1-6.

[8] Y.-K. Su, "6.02 - Nitride-Based LEDs and Superluminescent LEDs", P. Bhattacharya, R. Fornari, H. B. T.C. S. S., T. Kamimura, Editors, Elsevier, Amsterdam, 2011, pp. 28-100.

[9] V. K. Khanna, "Fundamentals of solid-state lighting: LEDs, OLEDs, and their applications in illumination and displays", CRC Press, 2014.

[10] LEDs Magazine, “Driving LED lamps - some simple design guidelines", 2007. .

[11] Lighting Answers, "Led Lighting Systems", https:// www.Irc.rpi.edu/programs/nlpip/publicationdetails.asp?id=885\&type=2 (Accessed: 2021).

[12] A. Thomas, "Experimental study on the effect of junction temperature on power LED's", Proceedings of the $19^{\text {th }}$ International Conference on Instrumentation, 2015, pp. 14-19.

[13] F. Rao, Z. Ge, J. Zhu, "Effect of temperature and current on luminous efficiency of high power LED", Advanced Materials Research, Vol. 347-353, 2012, pp. 310-313.

[14] R. Dwyer et al., "Evaluation of Harmonic Impacts from Compact Fluorescent Lights On Distribution Systems", IEEE Transactions on Power Systems, Vol. 10, 1995, pp. 1772-1779.

[15] C. Ekkaravarodome, N. Buree, K. Jirasereeamornkul, "An input current shaper using a classDE rectifier to meet IEC 61000-3-2 class-C standard processing a small part of the total power", Proceedings of the $9^{\text {th }}$ International Conference on Electrical Engineering/Electronics, Computer, Telecommunications and Information Technology, 2012. 
[16] P. Ptak, K. Górecki, J. Heleniak, M. Orlikowski, “Investigations of Electrical and Optical Parameters of Some LED Luminaires-A Study Case", Energies, Vol. 14, No. 6, 2021, p. 1612.

[17] Ł. Putz, M. Kurzawa, "Measurements and analysis selected power quality", Computer Applications in Electrical Engineering, Vol. 14, 2016, pp. 551-561.

[18] P. Ptak, K. Górecki, J. Zarębski, "Power supply circuits used in LED lamps", Elektryka, Vol. 1, 2016, pp. 31-38.
[19] K. J. Kumar, G. Bharath Kumar, R. S. Kumar, "Harmonic Impacts of Warm and Cool white LED Bulbs", Proceedings of the Global Conference for Advancement in Technology, Bangalore, India, 1820 October 2019.

[20] Ledex, "Iluminación LED eficiente", https://ledex. ec/. (Accessed: 2021).

[21] Schréder, "Proveedor líder de soluciones de iluminación inteligente independiente a nivel mundial", https://latin.schreder.com/es (Accessed: 2021). 